\title{
SISTEM MONITORING TEKANAN AIR PADA PDAM GIANYAR BERBASIS WEB
}

\author{
Ni Wayan Sumartini Saraswati ${ }^{1}$, I Wayan Agustya Saputra ${ }^{2}$ \\ ${ }^{1,2}$ Program Studi Teknik Informatika, STMIK STIKOM Indonesia, Denpasar, Bali, Indonesia \\ ${ }^{1}$ Email : sumartini.saraswati@stiki-indonesia.com, ${ }^{2}$ Email : agustya_saputra@yahoo.com
}

\begin{abstract}
ABSTRAK
Perusahaan Daerah Air Minum (PDAM) Kabupaten Gianyar adalah salah satu perusahaan milik daerah di Kabupaten Gianyar. PDAM Gianyar bertanggung jawab atas ketersediaan air bersih bagi konsumen di wilayah Gianyar dan sekitarnya. Dalam sistem distribusi air, PDAM melakukan pemantauan tekanan air dalam pipa sehingga air dijamin mengalir sampai ke pelanggan. Selama ini sistem pencatatan tekanan air pada manometer yang terpasang pada setiap zona tertentu dilakukan secara manual menggunakan kertas laporan. Kesulitan yang ditimbulkan adalah lambatnya hasil monitoring tekanan air yang dilaporkan oleh petugas pencatat ke petugas distribusi, sehingga proses distribusi air menjadi tersendat yang pada akhirnya merugikan pihak pelanggan dan PDAM sendiri. Penelitian ini bertujuan untuk membuat sistem yang dapat melakukan pencatatan tekanan air yang memudahkan kepala distribusi mendapat informasi secara cepat. Dengan tahap penelitian yang meliputi teknik pengumpulan data, analisis sistem, dan perancangan sistem untuk memaksimalkan penelitian serta melakukan implementasi sistem dan pengujian pada setiap sistem, maka dapat disimpulkan bahwa sistem yang sudah dibuat dapat berjalan dengan baik dan sesuai harapan. Fitur fungsional yang dihasilkan dalam penelitian ini adalah dashboard grafik tekanan air rata-rata per bulannya, pengolahan data master pegawai, pengolahan data master desa, pengolahan data master manometer, pengolahan data schedule, monitoring manometer oleh petugas, monitoring manometer oleh admin serta laporan monitoring manometer.
\end{abstract}

Kata Kunci : Sistem Informasi, Monitoring, Tekanan Air, Website, PDAM

\section{ABSTRACT}

Regional Water Company (PDAM) Gianyar Regency is one of the regionally owned companies in Gianyar Regency. Gianyar PDAM is responsible for the availability of clean water for consumers in the Gianyar region and its surroundings. In a water distribution system, the PDAM monitors water pressure in the pipeline so that water is guaranteed to flow to the customer. During this time the system of recording water pressure on the manometer installed in each particular zone is done manually using report paper. The difficulty caused is the slow monitoring of water pressure reported by the recording officer to the distribution officer, so that the water distribution process becomes stagnant which ultimately harms the customers and the PDAM itself. This study aims to create a system that can record water pressure which makes it easier for the distribution head to get information quickly. With the research phase which includes data collection techniques, system analysis, and system design to maximize research and implement systems and tests on each system, it can be concluded that the system that has been made can run well and as expected. The functional features generated in this study are the dashboard graph of the average water pressure per month, processing master employee data, processing village master data, processing master manometer data, processing schedule data, manometer monitoring by officers, manometer monitoring by admin and manometer monitoring report .

\section{Keywords : Information Systems, Monitoring, Water Pressure, Website, PDAM}

\section{PENDAHULUAN}

Kehadiran teknologi internet dalam era globalisasi telah terbukti membantu dan mempermudah pekerjaan yang terkait dengan kemudahan akses, jarak dan waktu. Semakin terjangkaunya internet di Indonesia menciptakan peluang pengembangan beragam sistem informasi perusahaan sehingga mendorong berbagai pelaku bisnis baik di kalangan pemerintah maupun swasta untuk berlomba memanfaatkannya[1].
Sistem informasi merupakan salah satu hal terpenting dalam suatu perusahaan. Dengan adanya sistem informasi maka organisasi atau perusahaan dapat menjamin kualitas informasi yang disajikan dan dapat mengambil keputusan berdasarkan informasi tersebut. Seiring perkembangan teknologi maka kebutuhan akan informasi yang cepat, tepat dan akurat sangat diperlukan. Karena itu, keberadaan sistem informasi sudah menjadi kebutuhan mutlak bagi perusahaan dalam menjalankan proses bisnisnya [2]. 
$\begin{array}{lrr} & \text { Monitoring dapat didefinisikan sebagai } \\ \text { suatu proses } & \text { mengukur, } & \text { mencatat, } \\ \text { mengumpulkan, } & \text { memproses } & \text { dan }\end{array}$ mengkomunikasikan informasi untuk membantu pengambilan keputusan [3]. Sistem informasi monitoring adalah sebuah aplikasi untuk mengetahui perubahan - perubahan yang terjadi akibat pergerakan variable secara kontinyu dalam kurun waktu tertentu. Informasi yang di tampilkan merupakan kombinasi dari teks, grafik, chart [4].

Salah satu perusahaan yang banyak menggunakan sistem informasi monitoring adalah perusahaan manufaktur untuk memonitor proses produksi dalam perusahaannya. Dalam mendukung kegiatan operasionalnya, perlu adanya sistem monitoring yang terkomputerisasi sehingga dapat memantau dan mendata kegiatan produksi, baik pengadaan bahan, penjadwalan produksi, serta pendataan setiap produk yang dihasilkan [5]. Sebuah perusahaan manufaktur acrylic membangun sistem informasi yang mampu memberikan informasi produksi secara cepat untuk mengatasi permasalahan seperti pengolahan data project order, sample order, sales order, material release, production, assembly, dan delivery order yang masih manual [6]. Hal ini juga dilakukan oleh sebuah perusahaan sepatu dalam mengendalikan produksi sepatu yang lebih efisien. Dari hasil perhitungan sistem diketahui kapan dan berapa jumlah bahan baku dan komponen yang dibutuhkan [7].

Sistem informasi monitoring juga diterapkan oleh perusahaan jasa seperti perusahaan konstruksi, property, telekomunikasi, perbankan, jasa keuangan dan pendidikan. Dalam perusahaan konstruksi monitoring dilakukan terhadap manajemen proyek sehingga setiap proyek dapat dipantau pelaksanaannya setiap saat [8] [9] [10].

Sebuah perusahaan property, manajemen Paltrow City yang menjual Bellini Tower Apartement mengembangkan sistem informasi yang dapat memonitoring status pembayaran dari semua unit apartement dalam satu tampilan [11]. Sistem informasi monitoring juga dapat dilakukan untuk memantau inventarisasi dan distribusi perangkat seperti yang dilakukan pada PT Telkom Cianjur dan Balai Riset Standardisasi Industri Bandar Lampung [12] [13]. Sistem monitoring data aset dan inventaris PT. TELKOM Cianjur berbasis web menghasilkan sistem monitoring perangkat yang digunakan oleh karyawan TELKOM sehingga sistem dapat memantau keberadaan perangkat yang digunakan oleh karyawan walaupun karyawan tersebut telah dipindah tugaskan. Dengan menggunakan basis data dalam sistem maka duplikasi pencatatan dapat dihindari.

Salah satu contoh pemanfaatan sistem informasi monitoring pada perbankan digunakan untuk memantau kejadian downtime pada mesin Anjungan Tunai Mandiri (ATM) yang disebabkan oleh kehabisan uang atau gangguan komunikasi dan gangguan perangkat keras, sehingga pelayanan mesin ATM dapat ditingkatkan[14].

Dalam bidang pendidikan sistem informasi monitoring digunakan sebagai salah satu alat penjaminan mutu baik di tingkat sekolah maupun perguruan tinggi. Monitoring dilakukan untuk memantau apakah pelaksanaan perkuliahan ataupun pengajaran telah sesuai dengan tujuan dan standar mutu yang telah ditetapkan institusi[15] [16].

Terdapat unsur kesamaan dari beberapa penelitian tersebut di atas dengan penelitian ini yaitu terlibatnya unsur pencatatan waktu dalam sistem monitoring. Perbedaan terletak pada konten monitoringnya.

PDAM Gianyar adalah sebuah Badan Usaha Milik Daerah (BUMD) yang bergerak dibidang pengelolaan air minum dan diselenggarakan atas dasar prinsip-prinsip ekonomi perusahaan. PDAM mempunyai tugas pokok menyelenggarakan pengelolaan air minum untuk meningkatkan kesejahteraan masyarakat. Sebagaimana fungsinya PDAM Kabupaten Gianyar melakukan penyusunan rencana dan program kerja serta pengendalian pengelolaan air minum, dan pelayanan umum penyediaan air minum kepada masyarakat.

Manometer yang terpasang pada setiap zona dan tempat tertentu memiliki tekanan yang berbeda - beda. Dalam proses pencatatannya ada beberapa kondisi yang menyebabkan proses monitoring menjadi terhambat. Kondisi tersebut antara lain adalah proses pencatatan manual dengan kertas, manipulasi data oleh petugas dan kebiasaan petugas untuk menunda pencatatan pada manometer. Kondisi tersebut menjadi permasalahan sehingga proses distribusi air menjadi tersendat bahkan merugikan pihak PDAM sendiri. Tekanan air yang melewati 
ketentuan tekanan manometer pada suatu zona tertentu juga menjadi permasalahan yang harus diselesaikan oleh pihak PDAM dengan sigap. Ketika menunggu hasil pencatatan yang lama dari petugas monitoring mengakibatkan keterlambatan informasi tentang tekanan air pada manometer yang mengalami penurunan tekanan air atau tekanan air diatas normal.

Dari uraian tentang pentingnya pemanfaatan sistem informasi monitoring di beberapa perusahaan dan guna mengatasi permasalahan yang dialami PDAM Gianyar maka diperlukan Sistem Informasi monitoring tekanan air untuk memantapkan upaya memenuhi kebutuhan informasi tekanan air di setiap cabang PDAM Gianyar dengan cepat, tepat, dan efisien. Sistem ini dibuat dengan mengkonversi data manual menjadi data digital ke dalam suatu database dan aplikasi terkomputersisasi dalam satu payung sistem yang disebut sebagai sistem informasi monitoring tekanan air berbasis web. Dengan sistem ini diharapkan akan memberikan peningkatan efektifitas dan efisiensi di bidang pengolahan, penyimpanan, penyajian informasi yang terkait dengan monitoring tekanan air.

Tujuan lain yang diharapkan agar memberi manfaat secara langsung sebagai sumber pendukung dalam pengambilan kebijakan atau keputusan yang berkaitan dengan monitoring tekanan air.

Sistem informasi monitoring tekanan air bertujuan untuk memudahkan petugas PDAM Kabupaten Gianyar untuk mencatat data monitoring tekanan air dan memberi informasi detail monitoring tekanan air pada bagian distribusi PDAM Kabupaten Gianyar.

\section{METODOLOGI}

Untuk mendapatkan sumber data dalam menyusun analisis sistem maka diawali dengan pengumpulan data. Pengumpulan data dilakukan dengan dua macam metode yaitu pengumpulan data primer dan pengumpulan data sekunder. Pengumpulan data primer berupa observasi dan wawancara di PDAM Gianyar. Observasi dilakukan dengan mengamati proses pencatatan dan monitoring tekanan air pada PDAM Gianyar.

Metode pengumpulan data sekunder dilakukan dengan metode kajian pustaka dan dokumentasi. Proses dokumentasi dilakukan dengan menganalisis dokumen - dokumen yang terlibat dalam proses pencatatan dan monitoring tekanan air di PDAM Gianyar.

Model pengembangan sistem dilakukan dengan model waterfall yang terdiri dari tahapan sebagai berikut :

1. Feasibility Study

2. Requirement Analysis

3. Design

4. Coding and Unit Testing

5. Integration, Implementation and System Testing

\section{Maintenance}

\section{HASIL DAN PEMBAHASAN}

Sistem dikembangkan dengan metode analisis terstruktur sehingga analisis sistem dilakukan dengan tools pemodelan berupa data flow diagram (DFD). Dalam proses pengolahan data sistem informasi ini terdapat beberapa kegiatan yang dilakukan oleh admin yaitu dapat melakukan login, melakukan edit, delete, selain itu admin dapat memberi jadwal kepada petugas untuk menginput hasil monitoring. Petugas juga dapat melakukan login, input dan edit dalam waktu yang sudah ditentukan oleh admin.

Berikut dalam gambar 1. Ditunjukkan diagram konteks sistem. Gambar 2,3 dan 4 adalah penjabaran lebih detail di level ke 1 untuk beberapa DFD sistem yang dianggap penting. 


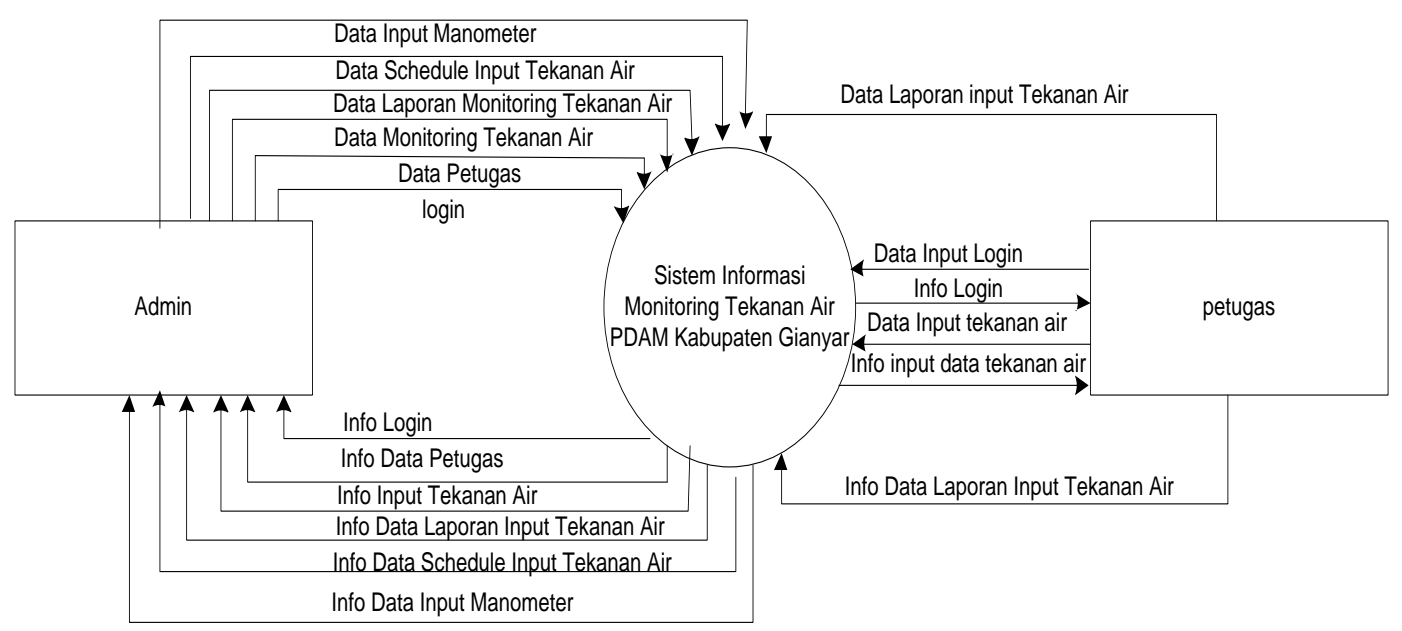

Gambar 1. Contex Diagram

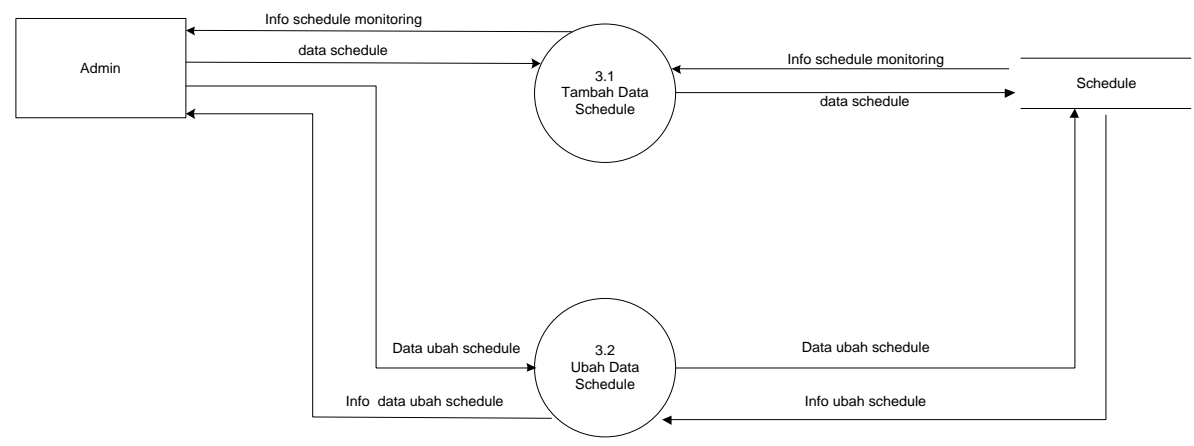

Gambar 2. DFD Level 1 Mengelola data schedule

Data flow diagram level 1 mengelola schedule menjelaskan bahwa admin dapat melakukan tambah schedule dan ubah schedule, untuk kemudian penambahan ataupun pengubahan data schedule disimpan ke dalam file schedule.

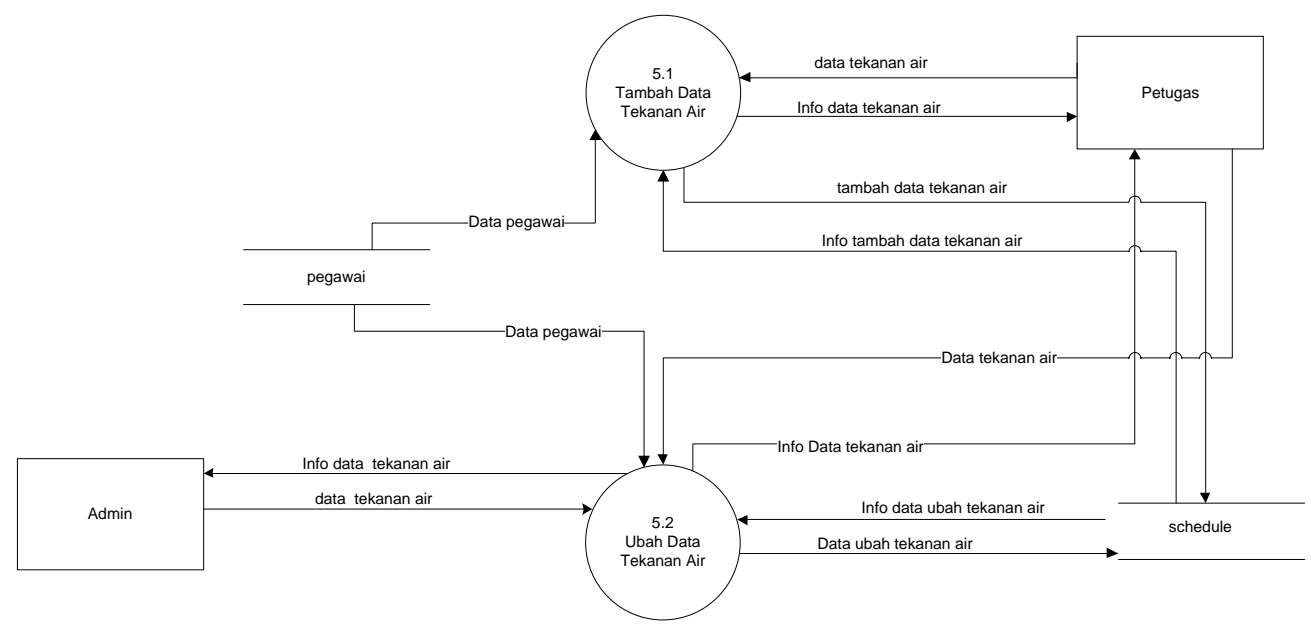

Gambar 3. DFD Level 1 Mengelola Data Tekanan Air 
Pada gambar 3 data flow diagram level 1 mengelola data tekanan air. Entitas petugas hanya dapat melakukan tambah dan ubah data tekanan air saja. Sedangkan entitas admin dapat melakukan ubah data monitoring dan tekanan air saja.

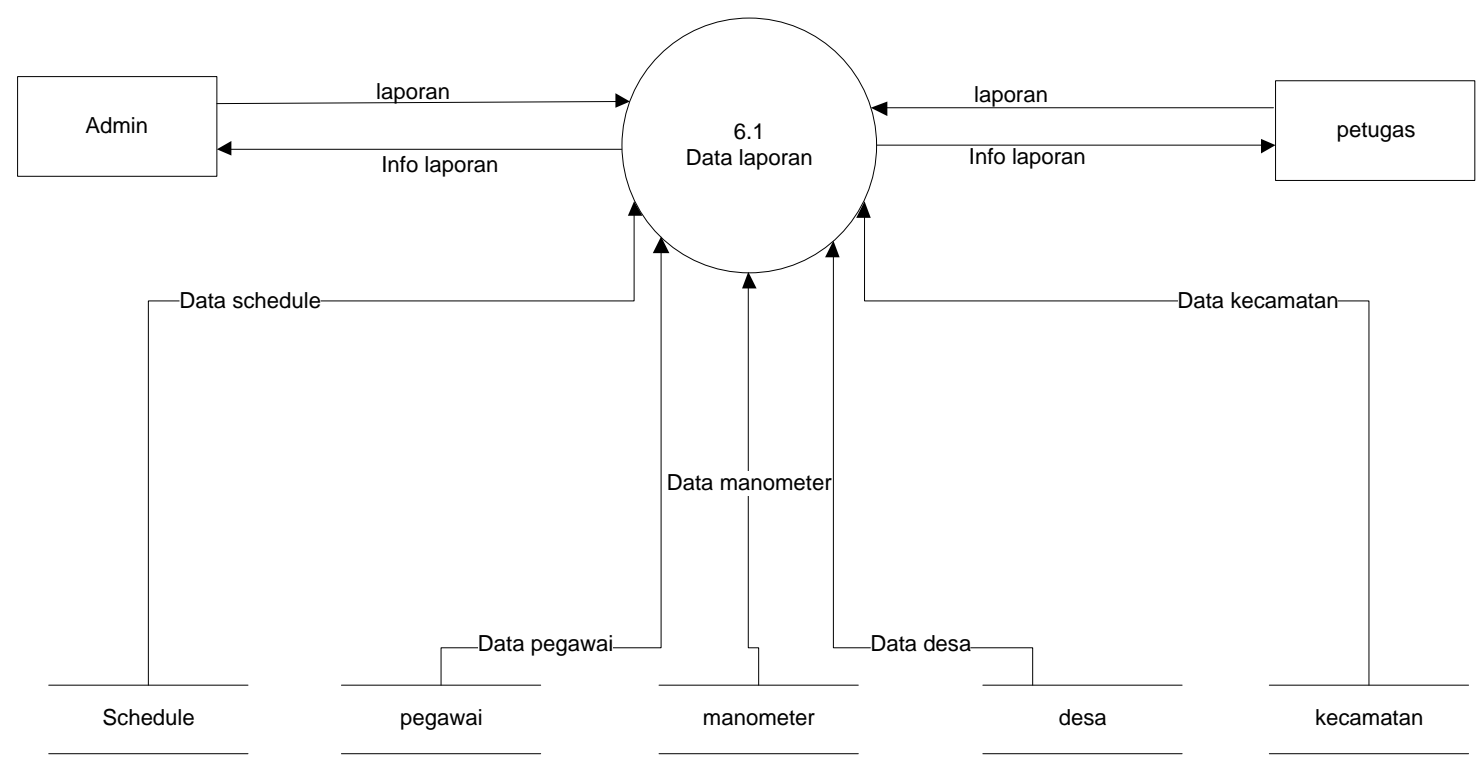

Gambar 4. DFD Level 1 Mengelola Laporan

Pada gambar 3.9 mengelola data laporan, admin dan petugas dapat melihat laporan hasil monitoring tekanan air yang ditambah oleh yang dikelola oleh petugas dan hasil perubahan oleh admin maupun petugas.

Basis Data yang dikembangkan untuk sistem adalah basis data relational. Basis data merupakan kelompok data yang saling berhubungan dan terorginisir dengan aturan tertentu sehingga dapat dimanfaatkan untuk berbagai kebutuhan, serta disimpan dalam media penyimpanan elektronik [18]. Analisis basis data dilakukan dengan bantuan Conceptual Data Model (CDM) yang dihasilkan melalui perangkat lunak Power Designer. CDM sistem seperti ditunjukkan oleh gambar 5 berikut ini. Sistem memiliki 5 entitas yaitu pegawai, schedule,desa, kecamatan dan manometer. Untuk mendapatkan rancangan database maka CDM diterjemahkan menjadi Physical Data Model (PDM) seperti ditunjukkan oleh gambar 6. 


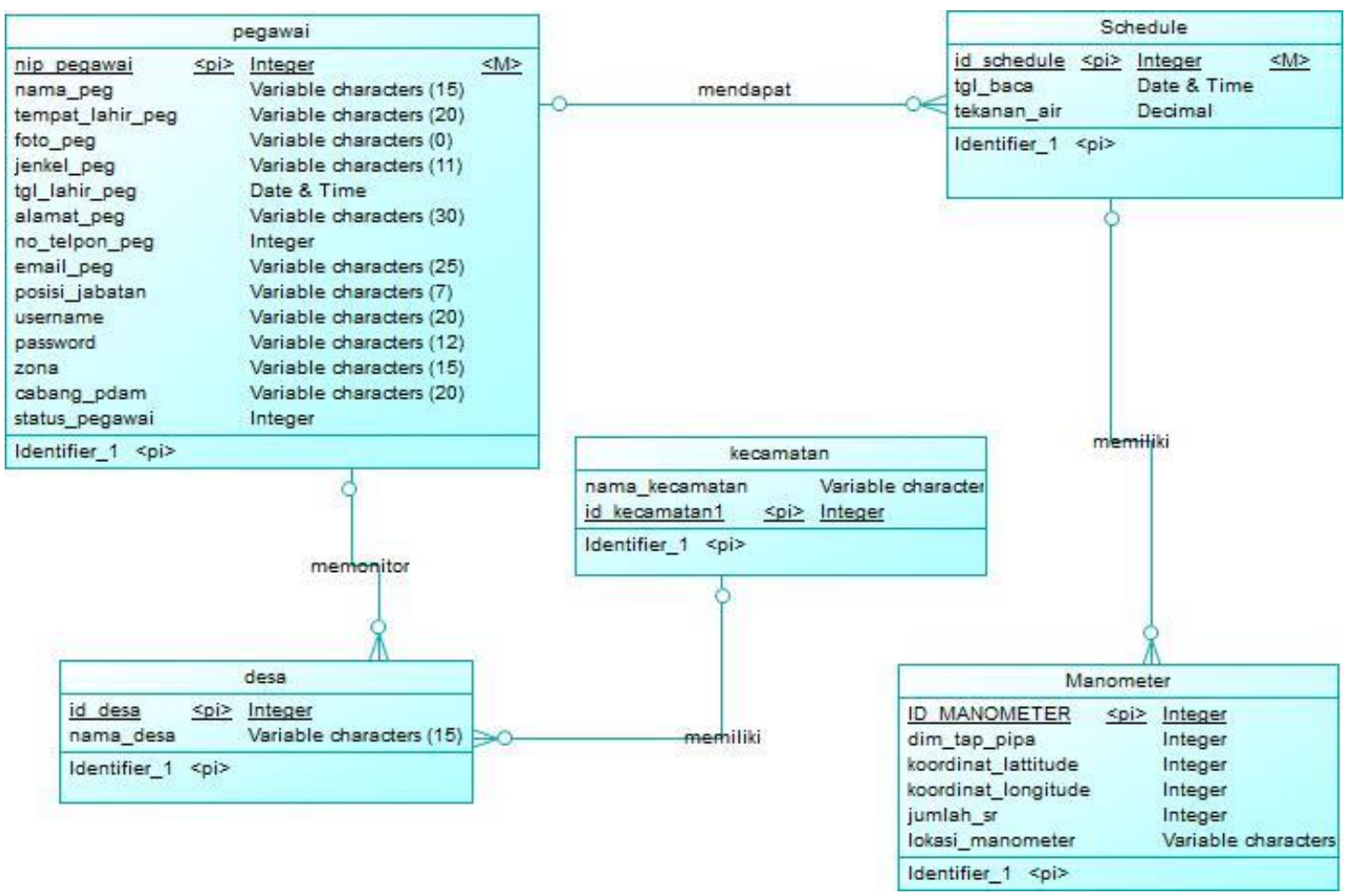

Gambar 5. CDM (Conceptual Data Model) Website Monitoring

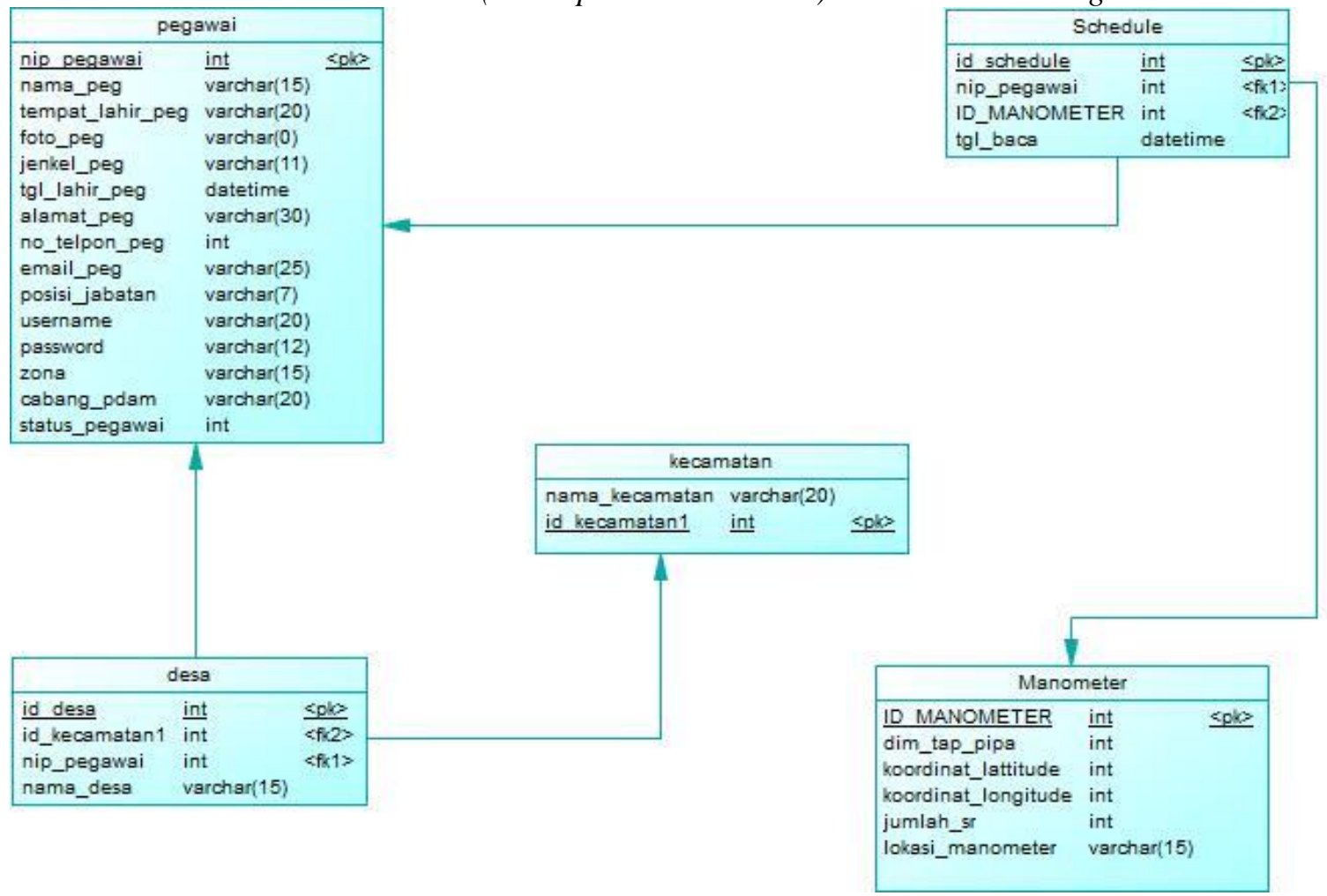

Gambar 6. PDM (Physical Data Model) Website Monitoring

Pengembangan sistem dilakukan dengan menggunakan bahasa pemrograman
PHP dan HTML. Hyper Text Markup Language (HTML), merupakan bahasa markup 
yang digunakan untuk membuat halaman web dan menampilkan berbagai informasi didalam sebuah browser. Dokumen html (atau halaman web) terdiri dari elemen-elemen yang menginstruksikanbrowser untuk menghasilkan tampilan sesuai dengan yang diinginkan [6].

Hasil implementasi dari pengembangan sistem dapat dilihat dalam bentuk halaman web yang ditunjukkan oleh gambar 7 hingga gambar 20 sebagai berikut.

\subsubsection{Implementasi Halaman Login}

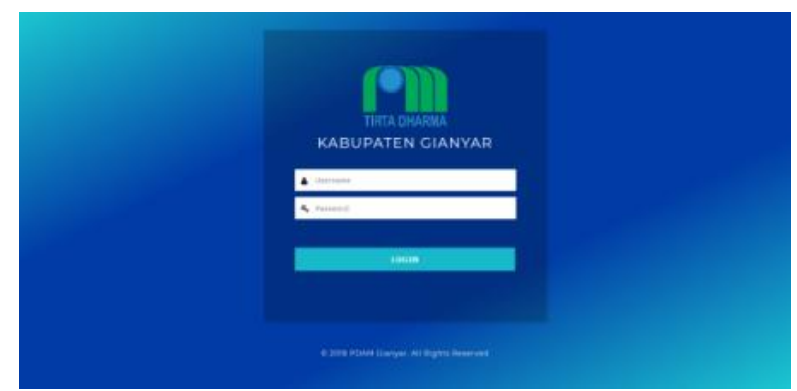

Gambar 7. Halaman Login

Gambar 7 adalah implementasi dari halaman login dari website Monitoring Tekanan Air pada PDAM Kabupaten Gianyar. Pada halaman ini terdapat dialog untuk verifikasi dan otentikasi username dan password untuk masuk ke dalam halaman web.

\subsubsection{Implementasi Halaman Dashboard (Admin)}

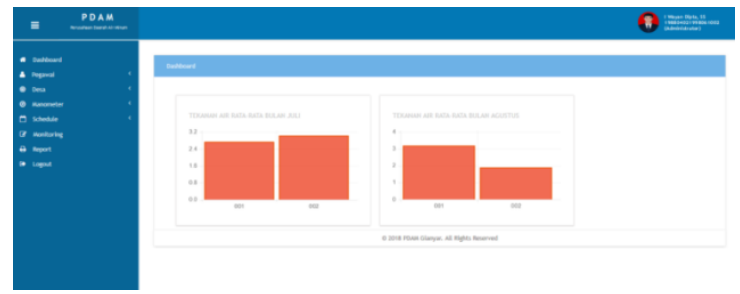

Gambar 8. Halaman Dashboard Admin

Gambar 8 adalah implementasi dari halaman dashboard admin setelah login. Pada halaman ini terdapat grafik tekanan air rata-rata untuk tiap bulannya dan tab menu di sebelah kiri.

\subsubsection{Implementasi Halaman Data Pegawai}

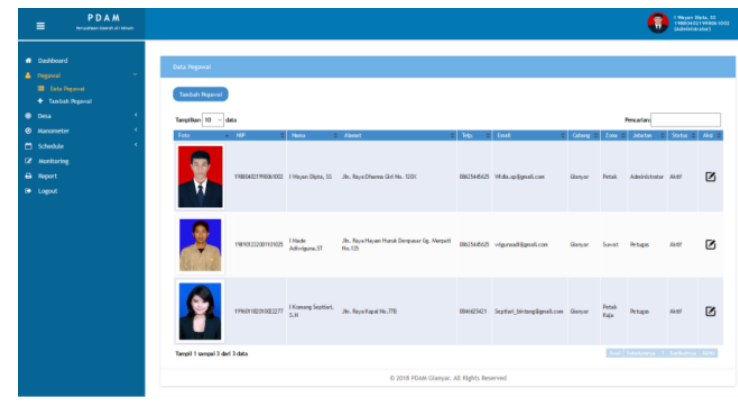

Gambar 9. Halaman Data Pegawai

Gambar 9 adalah merupakan implementasi dari halaman data pegawai. Pada halaman ini, admin dapat menambah dan mengubah data pegawai.

\subsubsection{Implementasi Halaman Tambah Data Pegawai}

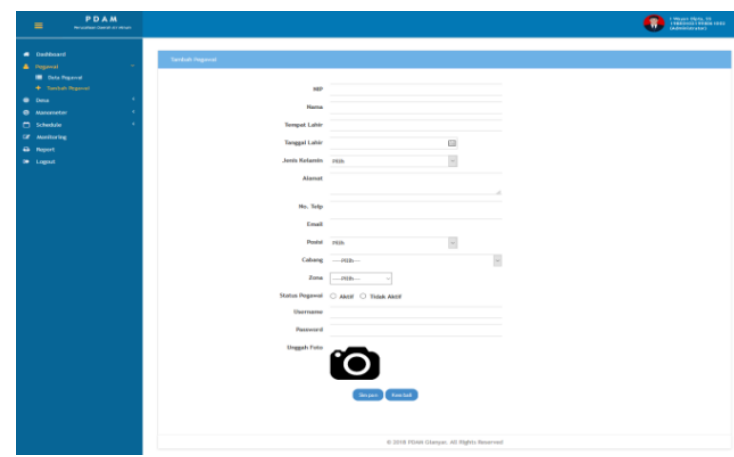

Gambar 10. Halaman Tambah Data Pegawai

Gambar 10 adalah implementasi halaman tambah data Pegawai. Pada halaman ini admin dapat menambah data pegawai dengan mengisi semua field.

\subsubsection{Implementasi Halaman Data Desa}

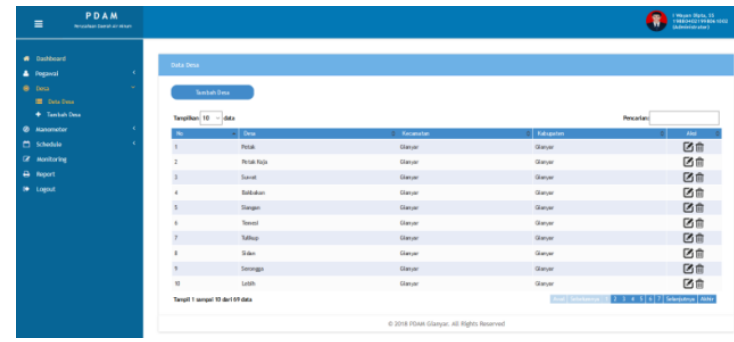

Gambar 11. Halaman Data Desa. 
Gambar 11 adalah implementasi dari halaman data desa. Pada halaman ini, data desa menunjukan tempat dimana desa yang memiliki lokasi manometer.

\subsubsection{Implementasi Halaman Tambah Desa}

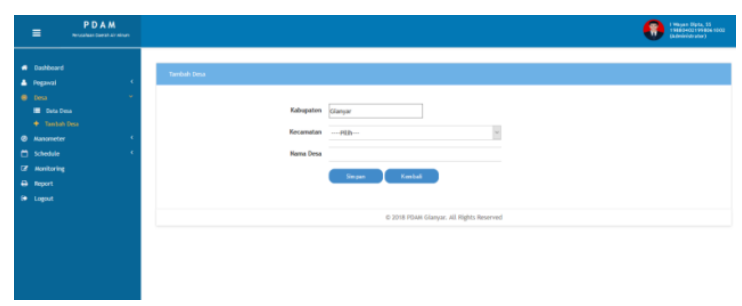

Gambar 12. Halaman Tambah Desa

Pada gambar 12 merupakan implementasi dari halaman tambah desa. Admin dapat menambah data desa untuk menentukan desa lokasi manometer terpasang.

\subsubsection{Implementasi Halaman Manometer}

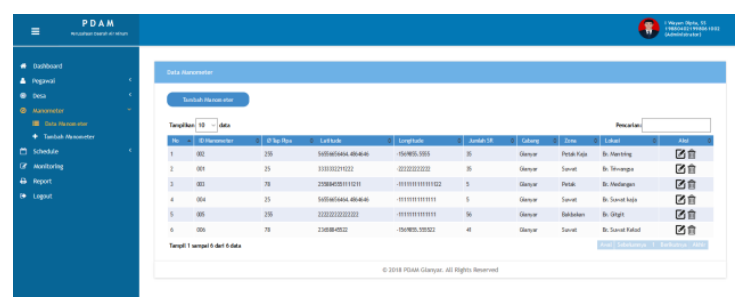

Gambar 13. Halaman Manometer

Gambar 13 adalah implementasi halaman manometer. Pada halaman ini disajikan informasi data semua manometer yang sudah ditambah oleh admin.

\subsubsection{Implementasi Halaman Tambah Manometer}

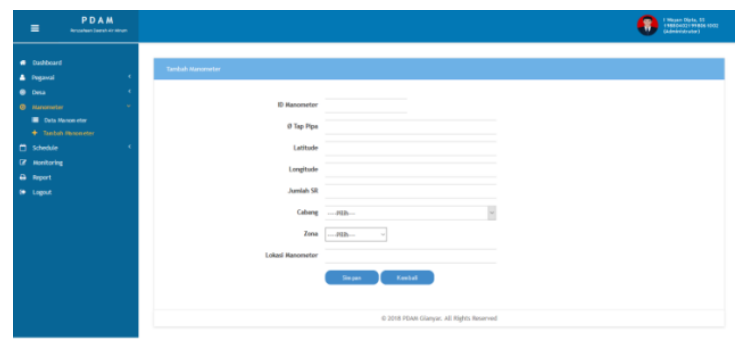

Gambar 14 adalah implementasi dari tambah manometer. Pada halaman ini admin dapat menambah data manometer dengan mengisi semua field yang tersedia, kemudian klik tombol simpan untuk menyimpan data dan kembali untuk membatalkan.

\subsubsection{Implementasi Halaman Data Schedule}

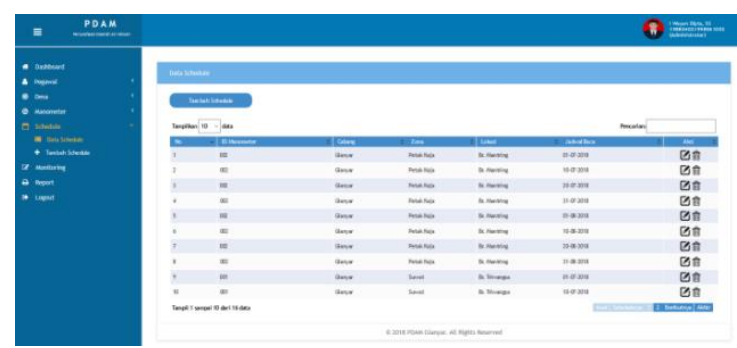

Gambar 15. Halaman Data Schedule

Pada gambar 15 adalah implementasi dari halaman data schedule. Pada halaman ini disajikan semua data schedule yang sudah ditambah sebelumnya oleh admin dan terdapat dua aksi yaitu untuk mengubah dan menghapus schedule.

\subsubsection{Implementasi Halaman Tambah Schedule}

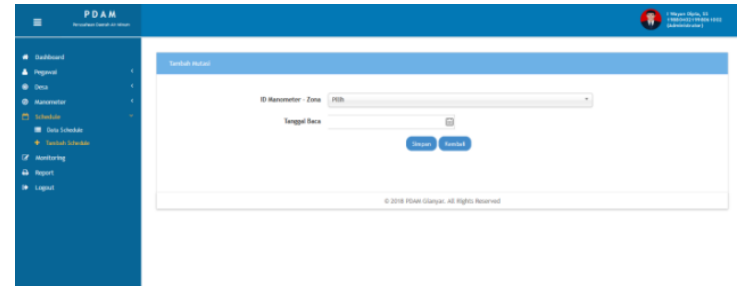

Gambar 16. Halaman Tambah Schedule

Gambar 16 adalah implementasi halaman tambah schedule. Pada halaman ini, Admin dapat menambahkan schedule monitoring tekanan air pada zona tertentu dan tanggal tertentu.

\subsubsection{Implementasi Halaman Monitoring (Admin)}

Gambar 14. Halaman Tambah Manometer 


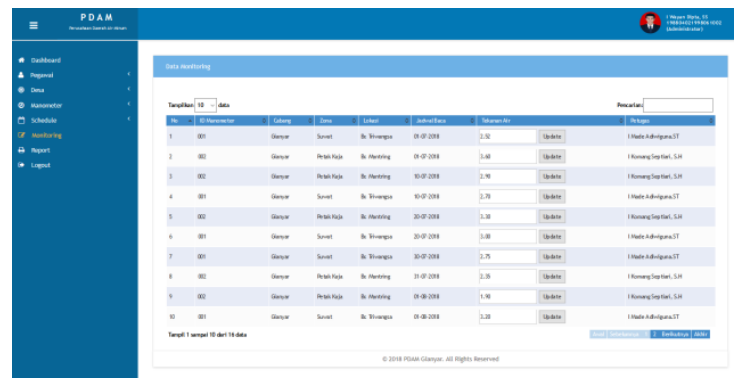

Gambar 17. Halaman Monitoring (Admin)

Gambar 17 adalah merupakan implementasi dari halaman monitoring. Admin hanya bisa melakukan perubahan pada hasil monitoring yang telah ditambah oleh petugas dengan cara mengisi field tekanan air yang akan diubah, kemudian klik tombol update untuk memperbarui hasil data monitoring tekanan air.

\subsubsection{Implementasi Halaman Monitoring (Petugas)}

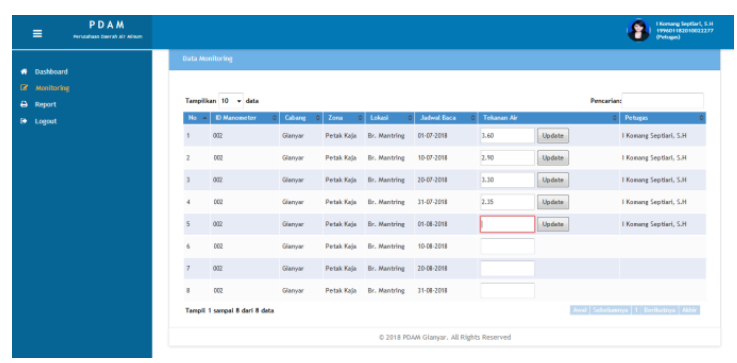

Gambar 18. Halaman Monitoring (Petugas)

Gambar 18 adalah implementasi halaman monitoring (petugas). Pada halaman ini, petugas dapat memasukan data tekanan air pada manometer dan schedule yang sudah ditetapkan oleh admin.

\subsubsection{Implementasi Halaman Report}

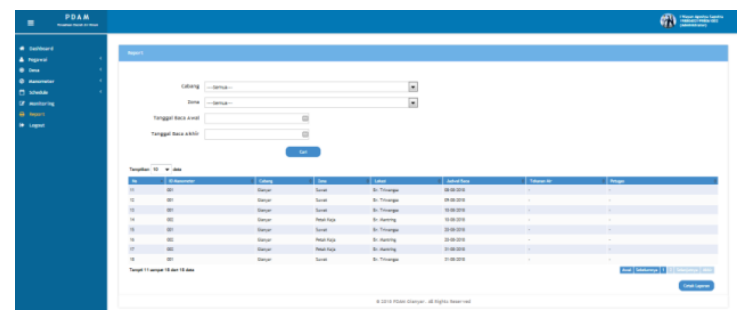

Gambar 19. Halaman Report

Gambar 19 adalah merupakan implementasi dari halaman report. Pada halaman ini, admin harus memilih cabang, zona dan pilihan tanggal yang ingin ditampilkan dalam report. Kemudian pilih tombol cari untuk menampilkan report.

\subsubsection{Implementasi Halaman Cetak Report}

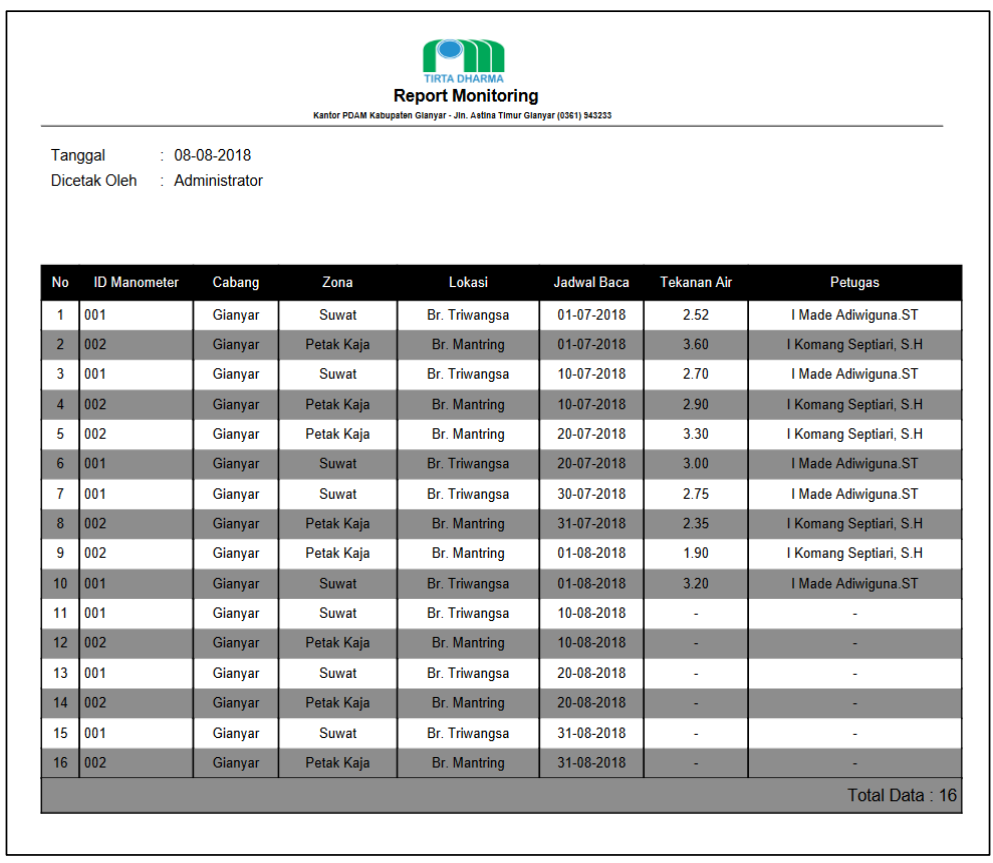

Gambar 20. Halaman Cetak Report 
Gambar 20 adalah implementasi halaman cetak report. Pada halaman ini akan tampil hasil monitoring tekanan air sesuai pencarian sebelumnya pada halaman report, kemudian disimpan atau bisa dicetak dalam bentuk hardcopy.

Proses pengujian sistem informasi monitoring tekanan air pada penelitian ini dilakukan dengan metode black box testing. Hasil pengujian ditunjukkan oleh tabel 1.

Tabel 1. Hasil Pengujian Sistem

\begin{tabular}{|c|l|l|}
\hline No & Fungsionalitas sistem & Hasil \\
\hline 1 & Login & Sesuai \\
\hline 2 & Tambah data pegawai & Sesuai \\
\hline 3 & Ubah data pegawai & Sesuai \\
\hline 4 & Tambah desa & Sesuai \\
\hline 5 & Ubah desa & Sesuai \\
\hline 6 & Tambah manometer & Sesuai \\
\hline 7 & Ubah manometer & Sesuai \\
\hline 8 & Tambah schedule & Sesuai \\
\hline 9 & Ubah schedule & Sesuai \\
\hline 10 & Tambah data monitoring & Sesuai \\
\hline 11 & Ubah data monitoring & Sesuai \\
\hline 12 & Pembuatan laporan monitoring & Sesuai \\
\hline
\end{tabular}

\section{SIMPULAN DAN SARAN}

Adapun simpulan dari penelitian ini antara lain :

1. Monitoring tekanan air pada manometer PDAM Gianyar berhasil dilakukan dengan implementasi sistem informasi monitoring yang dikembangkan dalam penelitian ini. Proses pencatatan dan pelaporan tekanan air pada manometer yang semula menggunakan catatan manual pada kertas digantikan oleh pencatatan data digital pada computer.

2. Sistem informasi monitoring ini dikembangkan dengan memanfaatkan teknologi internet dalam bentuk website sehingga proses pencatatan, hasil pelaporan dan monitoring tekanan air dapat dilakukan secara real time. Hal ini mengakibatkan kecepatan diperolehnya informasi terkait pengambilan tindakan untuk memelihara distribusi air bersih yang lancar dan merata pada PDAM Gianyar.

Adapun saran-saran yang bisa diberikan untuk program ini agar bisa didapatkan hasil yang maksimal adalah :

1. Diperlukannya pengolahan pemetaan lokasi untuk mengetahui keberadaan letak manometer di setiap zona.

2. Setiap schedule dikeluarkan, petugas agar mendapatkan notifikasi berupa email untuk mengetahui schedule yang dikeluarkan oleh admin.

\section{REFERENSI}

[1] M. I. Saputro, T. Sukendar, and A. Setyawan H, "Sistem Informasi Monitoring Perkembangan Proyek Berbasis Web Pada Pt . Wahana Reka Tekindo," J. Teknol. Inform. Komput., vol. 4, no. 1, 2018.

[2] Jogiyanto, "Analisis Dan Desain Sistem Informasi : Pendekatan Terstruktur Teori Dan Praktek Aplikasi Bisnis." Informatika, Bandung, 2005.

[3] J. F. A. Andry, "Sistem Informasi Monitoring Proyek Furniture Di Pt. Xyz," Stud. Inform. J. Sist. Inf., vol. 9, no. 2, pp. 213-220, 2016.

[4] A. Ilhamsyah, T. Lusiani, and T. Sutanto, "Rancang Bangun Sistem Informasi Monitoring Data Performansi Mitra Speedy Berbasis Web Pada Pt. Telkom Regional Timur (Persero)," JSIKA, vol. 1, no. 1, pp. 5-8, 2012.

[5] S. Kasus, D. C. V Nors, and W. Cianjur, "Analisa Dan Perancangan Sistem Monitoring Produksi Konveksi Abstrak," Media J. Inform., vol. 8, no. 2, pp. 52-61, 2016.

[6] N. Legowo and I. M. K. Yoga, "Perancangan Aplikasi Monitoring Produksi pada Perusahaan yang Memproduksi Acrylic," ComTech Comput. Math. Eng. Appl., vol. 3, no. 1, p. 676, 2017.

[7] Samsoni, "Perancangan Sistem Informasi Kontrol Produksi Sepatu (Studi Kasus: Pt. Asia Dwimitra Industri Tangerang)," $J$. 
Inform. Univ. Pamulang, vol. 2, no. 3, pp. 153-158, 2017.

[8] M. MUDJAHIDIN and N. DITA PAHANG PUTRA, "Rancang Bangun Sistem Informasi Monitoring Perkembangan Proyek Berbasis Web," J. Tek. Ind., vol. 11, no. 1, p. 75, 2017.

[9] Aprisa and S. Monalisa, "Rancang Bangun Sistem Informasi Monitoring Perkembangan Proyek Berbasis Web ( Studi Kasus : Pt . Inti Pratama Semesta )," J. Rekayasa dan Manaj. Sist. Inf., vol. 1, no. 1, pp. 49-54, 2015.

[10] D. P. Sari, S. J. Putra, and E. Rustamaji, "The development of project monitoring information system (Case study: PT Tetapundi Prima Kelola)," 2014 Int. Conf. Cyber IT Serv. Manag. CITSM 2014, no. November, pp. 39-43, 2014.

[11] P. S. Saputra, W. Budiawan, and S. Sriyanto, "Perancangan Sistem Informasi Monitoring Status Pembayaran Apartemen Berbasis Web (Studi Kasus: Paltrow City, Semarang)," Ind. Eng. Online J., vol. 5, no. 1, 2016.

[12] Mardiani, "Sistem Monitoring Data Aset Dan Inventaris Pt Telkom Cianjur
Berbasis Web," J. Ilm. Komput. dan Inform., vol. 2, no. 1, pp. 35-40, 2014.

[13] A. S. Putra and O. M. Febriani, "Sistem Informasi Monitoring Inventori Barang Pada Balai Riset Standardisasi Industri Bandar Lampung," J. Inform., vol. 13, no. 1, pp. 90-98, 2013.

[14] Djumhadi and R. Fadilah, "Sistem Monitoring Mesin Anjungan Tunai Mandiri (ATM )," Semin. Nas. Inform., vol. 2009, no. semnasIF, pp. 48-56, 2009.

[15] W. Priyanto, D. Nugroho, and B. Widada, "Sistem Informasi Monitoring Perkuliahan Berbasis Web di STMIK Sinar Nusantara Surakarta," J. TIKomSiN, pp. 53-158, 2015.

[16] E. Sutinah, G. N. Azima, and E. F. Imaduddin, "Sistem Informasi Monitoring Akademik Dan Prestasi Siswa Dengan Metode Waterfall," J. Inf. Eng. Educ. Technol., vol. 2, no. 1, pp. 47-59, 2018.

[17] R. A. Sukamto and M. Shalahuddin, "Rekayasa Perangkat Lunak Terstruktur dan Berorientasi Objek Edisi Revisi." Informatika, Bandung, 2018.

[18] Fathansyah, "Basis Data (revisi kedua)." Informatika, Bandung, 2015. 